\title{
The Effect of the Religious Environment on Teenage Birth Rates in the USA
}

\author{
Roland Kappe
}

r.kappe@ucl.ac.uk

\author{
School of Public Policy \\ University College London \\ 29/30 Tavistock Square \\ London WC1H 9QU \\ United Kingdom
}

\begin{abstract}
:
This article tests whether there exists a relationship between the religious environment and teenage birth rates. Specifically, it is hypothesized that in the USA, the presence of a greater number of religious congregations and a greater number of religious adherents in a county are associated with higher teenage birth rates in this county. The data analysis is based on public health records from the CDC, and county religiosity data from the "Religious Congregations and Membership Survey" by the Association of Religion Data Archives (ARDA)Association of Statisticians of American Religious Bodies (ASARB). The data analysis broadly supports the hypothesis.
\end{abstract}

Keywords:

Religion, Teenage birth rates, Fertility, Adolescence, US county-level analysis 


\section{Introduction}

Is there a relationship between living in a religious environment and teenage childbirth? If so, is it in the sense of lower teenage birthrates, as more traditional social norms and a focus on sexual abstinence before marriage would suggest, or is a more religious environment instead associated with an increase in teenage childbirth, due to different social norms, and the effects of religion on contraceptive use and abortion?

The literature on causes and consequences of teenage childbearing identifies a variety of individual, family, and community level factors that are associated with sexual behavior, pregnancy, and childbirth in adolescents (cf . Kirby and Lepore 2007). Many of these are social, economic, and demographic factors such as low income and poverty (Kirby et al 2001), education (Crane 1991) and race and ethnicity (Singh et al 2001).

This article aims to contribute to the literature on teenage childbearing by providing original empirical evidence on the question whether living in a religious environment affects teenage childbirth in the United States. Specifically, using county-level data, the analysis shows that there is a relationship between the teenage birth rate and the religious environment, measured as the countylevel density of religious congregations. The estimation results indicate that a more religious environment is associated with a higher teenage birth rate. These results hold when controlling for a variety of other important predictors, as well as state-level heterogeneity, and when applying a formal robustness analysis using Bayesian Model Averaging (BMA).

The following section introduces the potential causal mechanisms linking the religious environment and teenage birth rates and formulates opposing hypotheses regarding the expected direction of the effect. The third section provides details on the data and methods used. The fourth section presents the results of the data analysis, and the last section concludes by discussing limitations and possible policy implications. 


\section{Theory and Hypotheses}

Holding religious beliefs and practicing religion is often considered a virtue. Some scholars attribute a variety of normatively positive social outcomes, such as less crime (Evans et al. 1995), general "social capital" (Putnam 2000), and even economic growth (Barro and McCleary 2003) to religiosity. This paper provides some evidence that religious beliefs may in fact increase the incidence of a social outcome that is often considered undesirable: childbirth in adolescents.

The evidence for adverse effects and risks associated with childbirth in adolescents is ample. For a teenage mother, giving birth to a child drastically increases the likelihood of not finishing high school (Ahn 1994), heightens the risk of poverty (Moore et al. 1993, Hoffman et al. 1993), later welfare dependency (Moore 1978), and is even associated with higher mortality (Olausson et al. 2004). For the children, having a teenage mother comes with an increased risk of adverse developmental, intellectual and educational outcomes, lower school achievement (Baldwin and Cain 1980; Geronimus and Korenman 1993), and infant mortality (Olausson et al. 1999). In sum, one might object to the superlative, but still generally concur with Bill Clinton in his 1995 State of the Union Address, in saying that "[teenage childbearing is] our most serious social problem" (Washington Post 1995). This problem is especially widespread in the United States, as teen pregnancy and birth rates in the U.S. are the highest among industrialized countries (Darroch et al. 2001). The U.S. Centers for Disease Control and Prevention (CDC) considers prevention of teenage pregnancy as one of their priorities (CDC 2015). This renders an investigation into possible causes or risk factors especially necessary.

Existing studies have related teen pregnancy and childbirth to a variety of socioeconomic factors at the individual, family and community level. Among the most important factors are income (Finer and Henshaw 2006), poverty (Kirby et al 2001, Gold et al. 2002), education (Crane 1991), living in urban areas (Crane 1991, Stewart 2003), and race and ethnicity (Singh et al 2001, Henshaw 1997). Kirby and Lepore (2007) provide a systematic review of the literature.

The focus here, however, is on the effect of religion on the incidence of adolescent childbirth. While religion is a rather broad concept, most streams of the three Abrahamic religions that account 
for more than $85 \%$ of the U.S. population (ARDA 2008) subscribe to a sexual ethic and a view of reproductive medicine that is more restrictive than what is regulated by the laws in most industrialized democracies including the U.S. (cf. Srikanthan and Reid 2008).

The main question here, therefore, is whether there is a relationship between living in a religious environment and the incidence of teenage childbirth. In particular, this study proposes four possible microfoundations that might link a religious environment to teen childbirth. Figure 1 illustrates the main relationship and four potential causal mechanisms.

A religious environment could lead to a reduction in teenage childbirth mainly through mechanism (a.), abstinence, a reduced frequency of sexual intercourse in teenagers. This is the mechanism supported by followers of various denominations, assuming that religious faith and the moral rules associated with it lead to a reduced frequency of sex in adolescents, and specifically before marriage, which in turn leads to fewer underage pregnancies and births. There is some empirical evidence supporting this view (Beck et al. 1991, Brewster et al 1998).

Figure 1: Potential Causal Pathways

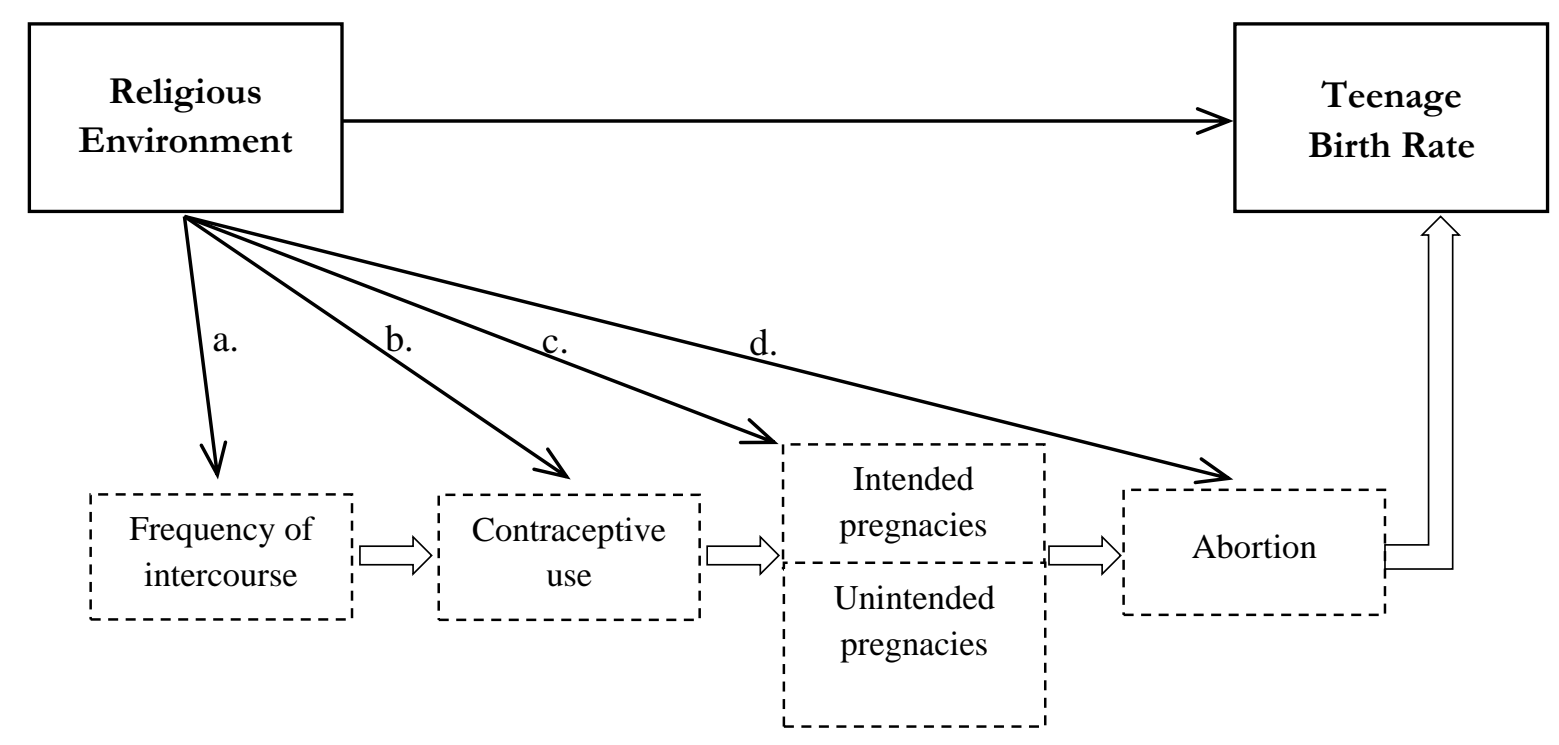


On the other hand, a religious environment could lead to an increase in teenage childbirth mainly via three mechanisms: causal pathway (b.) suggests an impact of religion on contraceptive use. Specifically, a religious environment could affect the availability of contraceptives via behavioral norms on the individual or family level (cf. Averett et al 2002, Jones et al 2005) or through more direct restrictions. Equally important could be an impact of a religious environment not only on the availability of contraceptives, but rather regarding education about contraceptive use (Kirby 2008, Santelli et al 2006), and, therefore, ultimately their correct and consistent use by adolescents (Studer and Thornton 1987). Both would - ceteris paribus - lead to an increase in unintended pregnancies and ultimately teenage childbirth, and there are several studies that show a negative relationship between religiosity and contraceptive use in general (Goldscheider and Mosher 1991), and especially in adolescents (Studer and Thornton 1987).

A third possible link (c.) relates to the question of the intendedness of the pregnancy. While a majority of teenage pregnancies are unintended, a substantial fraction of teenage pregnancies are intended (cf. Finer and Henshaw 2006). Mosher et al (2012) estimate around 23\% of all teen pregnancies to be intended. A religious environment can be expected to influence the social acceptability and individual desire for giving birth at young age. ${ }^{1}$

Finally, a fourth mechanism (d.) linking a religious environment and teenage childbirth is via the question of abortion. A religious environment may directly affect the likelihood of seeking an abortion on the individual, family or social level, but also via restricting the individual access to, and general availability of abortion providers through state laws. Tomal (2001) demonstrates in a research design similar to the one employed here that religiosity does have an effect on teen abortion rates. Using data from counties in 18 states that report this sensitive statistic, she shows that religion on the one hand influences state policies, such as the existence of 'parental involvement laws', and on the other hand also has an independent effect on abortion rates. Her study provides conclusive evidence for this relationship, but it should be noted that two factors might limit the generalizability of the study: firstly, the dependent variable suffers from limitations in terms of data availability; and secondly, there exists a significant number of young women who actually seek abortions outside their

\footnotetext{
${ }^{1}$ I would like to thank one of the anonymous reviewers for pointing out this additional mechanism.
} 
county - and often even state - of residence, in part due to restrictive abortion legislation, or simply lack of clinics. This is the main reason why this study instead treats the actual abortion rate, together with frequency of intercourse, contraceptive use, and intendedness of the pregnancy, as unobservable factors $^{2}$, and instead focuses on a dependent variable that can be measured approximately error-free: actual births to teenage mothers.

The present study is intended to test the main arrow, i.e. the net effect, or general association, between the religious environment and teenage birth rate. The literature discussed above and the theoretical propositions lead to the following hypotheses. The first hypothesis represents the view that religion leads to fewer teen pregnancies and thus births, mainly via mechanism (a.) sexual abstinence:

$H_{1}$ : Reduction-Hypothesis: A higher level of religiosity in a given county will lead to a lower teenage birth rate.

By contrast, the three alternative causal pathways suggest that religion does either not significantly reduce sexual activity in teenagers, or at least does not reduce it sufficiently to offset the countervailing effects of either of the following mechanisms: reduced use of contraceptives (b.), lower abortion rates (d.), or an increase in intended pregnancies (c.). The second hypothesis combines the predictions of these microfoundations:

$\mathrm{H}_{2}$ : Increase-Hypothesis: A higher level of religiosity in a given county will lead to a higher teenage birth rate.

Finally, a third hypothesis can be inferred from the literature discussed above, namely that not only the levels of teenage births, but also the effects of religiosity and other independent variables, may differ by ethnic/racial group, meaning that there exists group-related heterogeneity in the datagenerating process.

$H_{3}:$ Subgroup-Hypothesis: The effects of religiosity and other independent variables are different for ethnic/racial subgroups.

\footnotetext{
${ }^{2}$ It would however be interesting to see studies utilize or suggest inventive measures for these factors. While non-intrusive, observational measures for the frequency of intercourse might be somewhat difficult to obtain, perhaps fine-grained regional contraceptive sales data could provide some additional insights.
} 


\section{Data and Methods}

These hypotheses are tested using multiple regression models of aggregate level data of a cross section of U.S. counties in the year 2000. The rationale for using U.S. counties as the level of analysis is twofold. Individual level administrative data from birth certificates is limited in terms of available information due to privacy requirements. Individual level survey data, on the other hand, is of course in general suited to address this research question. Standard public opinion surveys do however not generally offer sufficiently large numbers of teenage pregnancy cases. Also, the need to rely on retrospections, and the non-trivial issue of handling selection effects, render the use of survey-based studies more difficult. Furthermore, with the research design chosen here, the dependent variable (teenage childbirth) and most independent variables can be measured accurately and reliably at the county level. Finally, in contrast to higher levels of aggregation which are standard in the literature, such as the U.S. states, or countries in cross-national studies, the U.S. counties offer a much more fine-grained picture. Many of the U.S. states consist of heterogeneous regions in terms of urbanity, income, population and religiosity, so that the greater aggregation leads to a greater confounding of the causal effects. Therefore, the basic units of analysis used here are the U.S. counties. The reporting procedures of the $\mathrm{CDC}$ are based on birth certificates and affect the availability of data in so far, as the dependent variable "teen childbirths" is measured on the county level, as "state and county are defined by the mother's place of residence recorded on the birth certificate" (CDC 2005); and for each state, "counties with fewer than 100,000 persons are combined together under the label Unknown County" (CDC 2005). Due to this restriction, this study has to follow the CDC's aggregation strategy and combines these smaller counties within each state into one aggregate residual county. The inclusion of a respective dummy-variable controls for systematic differences between these aggregated units and the other counties.

The main dependent variable is the number of births per 1000 women aged 15-19 years in the year 2000 for women residing in a given county, as reported by the CDC natality public use database (CDC 2005). In order to assess heterogeneity among different ethnic/racial groups, and in line with 
the public health literature discussed above, comparable numbers for teenage births per 1000 population for whites only, blacks only, and Hispanics only, are analyzed as well.

The independent variable of interest is the county-level religious environment. The availability of reliable data in this field, especially on fine-grained levels of aggregation, is generally low. As a consequence, this study utilizes two indirect religiosity measures based on the "Religious Congregations and Membership Survey" conducted in 2000 by the Association of Statisticians of American Religious Bodies (ASARB 2000): the number of congregations per 1000 population in a county, and the proportion of adherents in the population in a given county. The first measure, the number of congregations, is quasi-objective, as the ASARB keeps track of all religious bodies in a given community. The main independent variable is calculated as the number of congregations per 1000 inhabitants in a county, and is thus effectively a measure of the density of religious service providers, rather than a direct measure of religiosity. More direct operationalizations based on surveys, such as the frequency of church attendance, generally don't allow for fine-grained, countylevel estimates due to too few respondents per unit. Furthermore, Blanchard et al (2014) are able to show that the congregation density is a very strong predictor of a more direct religiosity measure, using data from the 'Social Capital Community Benchmark Survey', which includes factors such as membership in a religious organization, attending services and participation in additional activities such as prayer groups. The congregations-measure can thus be seen as a proxy for a religious environment that is available at the county level.

The second measure that can be extracted from the ASARB (2000) data, the 'number of adherents', is somewhat more problematic from a measurement point of view. While the number of congregations can be counted accurately from the outside, the adherent numbers by contrast are based on reports by the congregations themselves about how many members they have. This is problematic in at least two ways. On the one hand, there may be an incentive to over-report the number of followers or service attendees. On the other hand, there is considerable non-response from congregations, and the reliability of the measure has been questioned elsewhere (Finke and Scheitle 2005). The measure used here is already based on the improved estimates provided by Finke and Scheitle (2005). While it would also be very interesting to distinguish more clearly between different 
faiths and congregations to capture heterogeneity in sexual morals, this approach would arguably stretch the available data of the religiosity measure even further, creating the pretense of a level of accuracy that the data hardly meet. The study therefore is limited to the overall religious environment, measured as the congregation density and the number of adherents.

According to the Reduction-Hypothesis, we expect the teenage birth rate to be lower in counties with more congregations and adherents. In contrast, according to the Increase-Hypothesis, more congregations and adherents should be associated with higher teenage birth rates.

The existing literature has identified a number of important determinants of teenage childbirth, and the models below take factors such as county demographics, rurality, income, poverty, education and ethnic/racial composition into account. Specifically, the following variables are included in the model: the population of a county, and the percentage of the population under eighteen, both based on the 2000 census; the county's score on a rural-urban continuum, and the percentage of high-school graduates as a measure for education level, both obtained from the USDA's Economic Research Service; the median household income and the percentage of the population in poverty from the 'Small Area Income and Poverty Estimates (SAIPE)' provided by the U.S. Census Bureau; and to control for racial/ethnic factors when the aggregate birth rate is used, the percentage of white people is included as well. Finally, in order to capture any systematic effects due to the CDC's method of aggregating residual counties, a dummy variable for these cases is included as well. Table A1 in the appendix provides summary statistics for all variables.

The analysis uses multiple regression models to estimate the effect of the religious environment on teenage birth rates. Due to the skew of the respective underlying distributions, the congregations, adherents, population and income measures enter the regression models as their natural logarithm. The analysis moves from simple bivariate models to more complex techniques, including state fixed effects, and - in a second step - assesses the robustness of the predictors using a Bayesian Model Averaging technique. 


\section{Results}

Is there a relationship between a religious environment and teenage birth rates at the county level? The main results of OLS models of the teenage birth rate can be found in Table 1 and provide support for the Increase-Hypothesis. Looking first at the simple bivariate relationships, Model 1 shows that there is a significant positive relationship between the number of congregations and teenage birth rates. The adherents-measure on the other hand seems to be uncorrelated with the teenage birth rate.

While this is a good first indication, the next question is of course whether these results hold up once other county characteristics are taken into account. Models 3 and 4 include a variety of factors that have been found to be associated with teenage birth rates, specifically county demographics, education, income, poverty, race and urbanity.

The important finding here is that the effect of the religious environment remains positively and significantly related to the teenage birth rate, even when controlling for a variety of standard predictors from the literature. The effect of a one unit increase in the congregation density measure is an increase of 5.4 childbirths per 1000 teenage women. This means in other words that going from a county with relatively few religious congregations (around one standard deviation below the mean would be for example Essex County, Massachusetts), to a county with many religious congregations (one standard deviation above the mean, e.g. Taylor County, Texas), is associated with an increase in the birth rate of around 5.7 per 1000 teenage women; all the while of course controlling for other factors, such as differences in income, education, population and rurality.

The other predictors behave as expected. Having a younger population leads to an increase in teenage childbirths, while more rural counties and counties with a predominantly white population have lower teenage birth rates. In line with existing work, education and income exhibit some of the strongest effects on teenage birth rates. Education, measured as the population with a high school degree, significantly reduces the teenage birth rate. As an example, going from one of the most educated counties where $94 \%$ have a high school diploma (e.g. Washington County, Minnesota), to the least educated county with only around 50\% high school graduates (Hidalgo County, Texas), the teenage birth rate should increase by around 42 births per 1000 women aged 15-19. 
Table 1: Predictors of County-Level Teenage Birth Rates

\begin{tabular}{|c|c|c|c|c|c|}
\hline & (1) & (2) & (3) & (4) & $(5)$ \\
\hline Congregations & $\begin{array}{l}7.627 * * * \\
(1.883)\end{array}$ & & $\begin{array}{l}5.389 * * \\
(1.820)\end{array}$ & $\begin{array}{l}5.409 * * \\
(1.825)\end{array}$ & $\begin{array}{l}5.606^{*} \\
(2.621)\end{array}$ \\
\hline Adherents & & $\begin{array}{l}-0.074 \\
(0.593)\end{array}$ & & $\begin{array}{l}-0.087 \\
(0.466)\end{array}$ & $\begin{array}{l}-0.478 \\
(0.378)\end{array}$ \\
\hline Population & & & $\begin{array}{l}-0.244 \\
(0.737)\end{array}$ & $\begin{array}{l}-0.304 \\
(0.804)\end{array}$ & $\begin{array}{l}-0.580 \\
(0.641)\end{array}$ \\
\hline Population < 18 & & & $\begin{array}{l}150.856^{* * *} \\
(18.816)\end{array}$ & $\begin{array}{l}150.795^{* * *} \\
(18.837)\end{array}$ & $\begin{array}{l}93.903 * * \\
(28.614)\end{array}$ \\
\hline High school grad. & & & $\begin{array}{l}-93.825 * * * \\
(12.660)\end{array}$ & $\begin{array}{l}-93.874 * * * \\
(12.675)\end{array}$ & $\begin{array}{l}-146.493 * * * \\
(21.266)\end{array}$ \\
\hline Income & & & $\begin{array}{l}-41.634 * * * \\
(5.083)\end{array}$ & $\begin{array}{l}-41.651 * * * \\
(5.088)\end{array}$ & $\begin{array}{l}-32.021 * * * \\
(3.874)\end{array}$ \\
\hline$\%$ Poor & & & $\begin{array}{l}-54.687 * \\
(26.495)\end{array}$ & $\begin{array}{l}-54.743^{*} \\
(26.522)\end{array}$ & $\begin{array}{l}-106.927 * * \\
(33.492)\end{array}$ \\
\hline Rural - Urban & & & $\begin{array}{l}-1.929 * * \\
(0.650)\end{array}$ & $\begin{array}{l}-1.920 * * \\
(0.652)\end{array}$ & $\begin{array}{l}-1.594 * \\
(0.653)\end{array}$ \\
\hline$\%$ White & & & $\begin{array}{l}-37.985 * * * \\
(4.066)\end{array}$ & $\begin{array}{l}-37.950 * * * \\
(4.074)\end{array}$ & $\begin{array}{l}-36.660 \text { *** } \\
(5.712)\end{array}$ \\
\hline Aggregated Counties & & & $\begin{array}{l}-4.351 \\
(3.213)\end{array}$ & $\begin{array}{l}-4.127 \\
(3.430)\end{array}$ & $\begin{array}{l}-4.605 \\
(2.337)\end{array}$ \\
\hline Constant & $\begin{array}{l}46.090 \\
(0.903)\end{array}$ & $\begin{array}{l}44.234 \\
(2.052) \\
\end{array}$ & $\begin{array}{l}572.516 \\
(55.554)\end{array}$ & $\begin{array}{l}573.169 \\
(55.717)\end{array}$ & $\begin{array}{l}534.223 \\
(50.812)\end{array}$ \\
\hline State Fixed Effects & No & No & No & No & Yes \\
\hline $\mathrm{R}^{2}$ & 0.03 & 0.00 & 0.68 & 0.68 & 0.84 \\
\hline $\mathrm{N}$ & 504 & 504 & 504 & 504 & 504 \\
\hline
\end{tabular}


Similarly, the county's economic situation has a strong effect on teenage birth rates, with a higher median income associated with fewer teenage childbirths. The median income-measure is of course also strongly correlated with the poverty rate $(r=-0.80)$. Based on the literature, both are included in the analysis. Taken by itself, each economic measure exhibits the expected effect. Higher income is associated with lower teenage birth rates $(r=-0.62)$, while higher poverty is associated with higher teenage birth rates $(r=0.69)$. When both are included in the analysis, the poverty coefficient reverses its sign due to multicollinearity. Both income and poverty are however strong predictors of the teenage birth rate (as a joint F-test confirms), and are therefore kept in the model. ${ }^{3}$

Having controlled for these important differences, neither the county population size, nor the dummy variable capturing any systematic differences of the CDC's 'residual' counties show a significant effect. Overall, the explanatory power of the model is quite high. Taken together, these predictors explain around $68 \%$ of the variation in county-level teenage birth rates.

Ultimately, this being observational data, there might of course be other omitted variables. Various differences in terms of state level political conditions, specific policies (Joyce and Kaestner 1996, Norrander and Wilcox 1999, Levine 2003), and other socio-cultural factors (Kirby et al 2005, Gelman 2009) come to mind, as well as more generally unobserved heterogeneity between different regions in the Unites States. In order to minimize any of these possible confounders, Model 5 additionally includes state fixed effects. In practice this means that all observable and unobservable between-state variation is removed. This estimation strategy can be expected to attenuate some of the effects. While the model now naturally explains a lot more of the overall variance, the effects remain substantively the same. The religious environment still has a similarly-sized, positive, and statistically significant effect on teenage birth rates, even when controlling for a variety of predictors, and the observed and unobserved state-to-state differences. The state fixed effects model provides strong evidence in support of the Increase-Hypothesis.

Turning to the question whether the effects vary by subgroup, Table 2 provides estimation results. The columns show separate results for white, black and Hispanic teenagers, respectively.

\footnotetext{
${ }^{3}$ Judging from additional tests using variance inflation factors (VIF), multicollinearity is not an overarching concern, especially not with respect to the independent variable of interest. Additional results are available upon request.
} 
Table 2: Analysis by Racial/Ethnic Subgroups

\begin{tabular}{|c|c|c|c|}
\hline & (White) & (Black) & (Hispanic) \\
\hline \multirow[t]{2}{*}{ Congregations } & $0.571 * *$ & $0.863 *$ & 0.667 \\
\hline & $(0.184)$ & $(0.395)$ & $(0.516)$ \\
\hline \multirow[t]{2}{*}{ Adherents } & 0.008 & $-0.171^{*}$ & -0.036 \\
\hline & $(0.013)$ & $(0.073)$ & $(0.056)$ \\
\hline \multirow[t]{2}{*}{ Population } & -0.037 & -0.027 & $0.278 * *$ \\
\hline & $(0.020)$ & $(0.125)$ & $(0.099)$ \\
\hline \multirow[t]{2}{*}{ Population < 18} & $5.443 * * *$ & 2.870 & 1.831 \\
\hline & $(0.754)$ & (3.502) & (3.710) \\
\hline \multirow[t]{2}{*}{ High school grad. } & -0.042 & 0.138 & $-9.459^{*}$ \\
\hline & $(0.612)$ & $(2.210)$ & (3.843) \\
\hline \multirow[t]{2}{*}{ Income } & $-1.441 * *$ & $-3.765 * * *$ & 0.242 \\
\hline & $(0.425)$ & $(0.879)$ & (1.138) \\
\hline \multirow[t]{2}{*}{$\%$ Poor } & -5.041 & -9.319 & -5.712 \\
\hline & (3.118) & $(5.448)$ & (3.368) \\
\hline \multirow[t]{2}{*}{ Rural - Urban } & $-0.059^{*}$ & $-0.281 * *$ & 0.084 \\
\hline & $(0.024)$ & $(0.098)$ & $(0.133)$ \\
\hline \multirow[t]{2}{*}{ Aggregated Counties } & -0.051 & 0.103 & -0.973 \\
\hline & $(0.075)$ & $(0.561)$ & $(0.498)$ \\
\hline \multirow[t]{2}{*}{$\%$ White/Black/Hispanic } & 0.015 & 2.156 & 0.182 \\
\hline & $(0.458)$ & $(1.197)$ & (1.609) \\
\hline \multirow[t]{2}{*}{ Constant } & $16.302 * *$ & $46.603 * * *$ & 4.905 \\
\hline & $(4.822)$ & $(9.497)$ & $(9.398)$ \\
\hline State Fixed Effects & Yes & Yes & Yes \\
\hline $\mathrm{R} 2$ & 0.73 & 0.40 & 0.44 \\
\hline $\mathrm{N}$ & 504 & 504 & 504 \\
\hline
\end{tabular}


The dependent variable is the number of teenage births for each group per 1000 population, and the effects are, therefore, in terms of magnitude not directly comparable to the overall results presented above. All models now use state fixed effects, i.e. all between-state variance is taken into account. The religious environment remains a significant predictor of teenage childbirths for whites and blacks, and the direction of the effect is positive for all three groups, indicating some support for the IncreaseHypothesis. Interestingly, in the model for black teens, the adherents-measure shows a negative effect. While the caveats with respect to this variable have already been discussed above, this could point into an interesting direction. Perhaps the impact of the religious environment is more nuanced in this case, with overall religiosity in terms of belonging to a church having a reducing effect, which is then partly offset by a positive effect of religious diversity. While this is quite speculative, it would be interesting to see future research into the effects of the religious environment in terms of diversity. The explained variance and directions of effects are similar for white teens compared to the models of the overall teenage birth rate, and the predictive power and pattern of results is generally somewhat less clear cut for blacks and Hispanics.

\section{Robustness Checks}

One of the most fundamental problems in the analysis of observational, cross-sectional data is model uncertainty. Many substantive debates in the social sciences revolve around the question which independent variables are to be included in a given model. As a consequence, every study combines a number of independent variables $\mathrm{x}_{1}, \ldots, \mathrm{x}_{\mathrm{k}}$, and reports the estimation results. Despite theoretical guidance, the true data generating process, i.e. the set of variables that should be included in the model, is of course unknown. As a consequence, a given researcher's preferred variable $\mathrm{x}_{1}$ shows a significant effect if $\mathrm{x}_{2}+\mathrm{x}_{3}$ also enter the regression equation, but not anymore once $\mathrm{x}_{4}$ is added. While this problem lead Achen (2002) to propose his "rule of three" advice in the absence of a very clear theoretical model, others have proposed formal tests for the robustness of a given model specification. Starting with Leamer (1985), who used global sensitivity analyses and a knife-edged "extremebounds-approach" to judge robustness, more recent approaches (Sala-i-Martin 1997, Montgomery and 
Nyhan 2010, Magnus et al 2010) allow us to analyze a whole distribution of parameter values obtained from global sensitivity analyses. These procedures are also known as Bayesian Model Averaging (BMA).

The basic BMA procedure, which is also employed here, obtains a number of potential independent variables from the literature, and estimates - for each of these variables - a large number of regression models, permuting all possible combinations of the other independent variables in the model. Instead of just one point estimate, this procedure yields a distribution of coefficient estimates over all possible model combinations. This distribution can subsequently be used to judge the robustness of a certain independent variable.

Table 3 provides the means, standard deviations and lower and upper bounds of the posterior coefficient distributions, as well as the posterior inclusion probabilities for all independent variables included in the models above, and for a variety of additional potential predictors. ${ }^{4}$

The overall picture is clearer than one might have expected. The religious environment in a given county exerts a robust influence on teenage birth rates. The effect is always positive, regardless of model specification, and the posterior inclusion probability suggests that it is an important predictor of teenage birth rates. This means that the evidence in support of the Increase-Hypothesis presented here is robust with respect to model uncertainty.

Figure 2 provides a graphical representation of the posterior distributions for all potential independent variables. Apart from the variables that have already been included based on theory, namely religion, income, education, population under 18 , and the racial/ethnic composition, the crime rate of the county also appears to be associated with the teenage birth rate. Absent a clear theoretical model, this should of course not be interpreted as evidence of a causal relationship. That being said, Pickett et al (2005) make an argument that teenage childbearing and crime "reflect genderdifferentiated responses to low social status".

\footnotetext{
${ }^{4}$ The BMA analysis allows for testing the robustness of the model underlying Table 1 by running all possible model combinations $\left(2^{\mathrm{k}}=65536\right)$; and, for each variable, retrieves the posterior distribution of coefficients as well as the posterior probability mass for all models in which the variable was included, i.e. the posterior inclusion probability (PIP). PIP is in this sense a measure of whether the variable belongs into the model. The independent variables had to be z-standardized for comparability. The results were obtained using the 'bma' Stata program by DeLuca and Magnus (2011).
} 
Table 3: Results of Bayesian Model Averaging

\begin{tabular}{lrrrrr}
\hline & Mean & SE & PIP & Lower & Upper \\
\hline Congregations $(\log )$ & 3.37 & 0.76 & 1.00 & 2.60 & 4.13 \\
Adherents $(\log )$ & 0.01 & 0.13 & 0.05 & -0.12 & 0.13 \\
Population $(\log )$ & -0.03 & 0.19 & 0.06 & -0.21 & 0.16 \\
Income $(\log )$ & -6.38 & 1.17 & 1.00 & -7.55 & -5.21 \\
\% HS graduates & -5.19 & 0.92 & 1.00 & -6.10 & -4.27 \\
\% White & -0.65 & 1.10 & 0.32 & -1.75 & 0.45 \\
Population <18 & 4.54 & 0.67 & 1.00 & 3.87 & 5.20 \\
Rural - Urban & -0.16 & 0.54 & 0.12 & -0.70 & 0.38 \\
Unemployment & -0.32 & 0.65 & 0.25 & -0.97 & 0.32 \\
Crime rate & 4.27 & 0.58 & 1.00 & 3.69 & 4.86 \\
\% Black & 5.31 & 1.08 & 1.00 & 4.22 & 6.39 \\
Population $>$ 65 & 0.67 & 1.08 & 0.35 & -0.41 & 1.75 \\
\% Social Security & 1.53 & 1.34 & 0.63 & 0.19 & 2.87 \\
\% Poor & -4.64 & 1.26 & 0.99 & -5.91 & -3.38 \\
\% Hispanic & 5.65 & 1.01 & 1.00 & 4.64 & 6.66 \\
\% Commuters & -0.03 & 0.16 & 0.06 & -0.19 & 0.13 \\
\hline
\end{tabular}

Notes: Results of Bayesian Model Averaging procedure over all possible model combinations. Dependent Variable: Births per 1000 women age 15-19 years. All independent variables are z-standardized to allow direct comparison. Mean is the average coefficient estimate, over all models, weighted. SE is the standard deviation of the posterior distribution. PIP is the posterior inclusion probability, and lower and upper bounds are mean \pm 1 s.d. of the posterior distribution (cf. DeLuca and Magnus 2011, Magnus et al 2010) 
Figure 2: Results of Bayesian Model Averaging

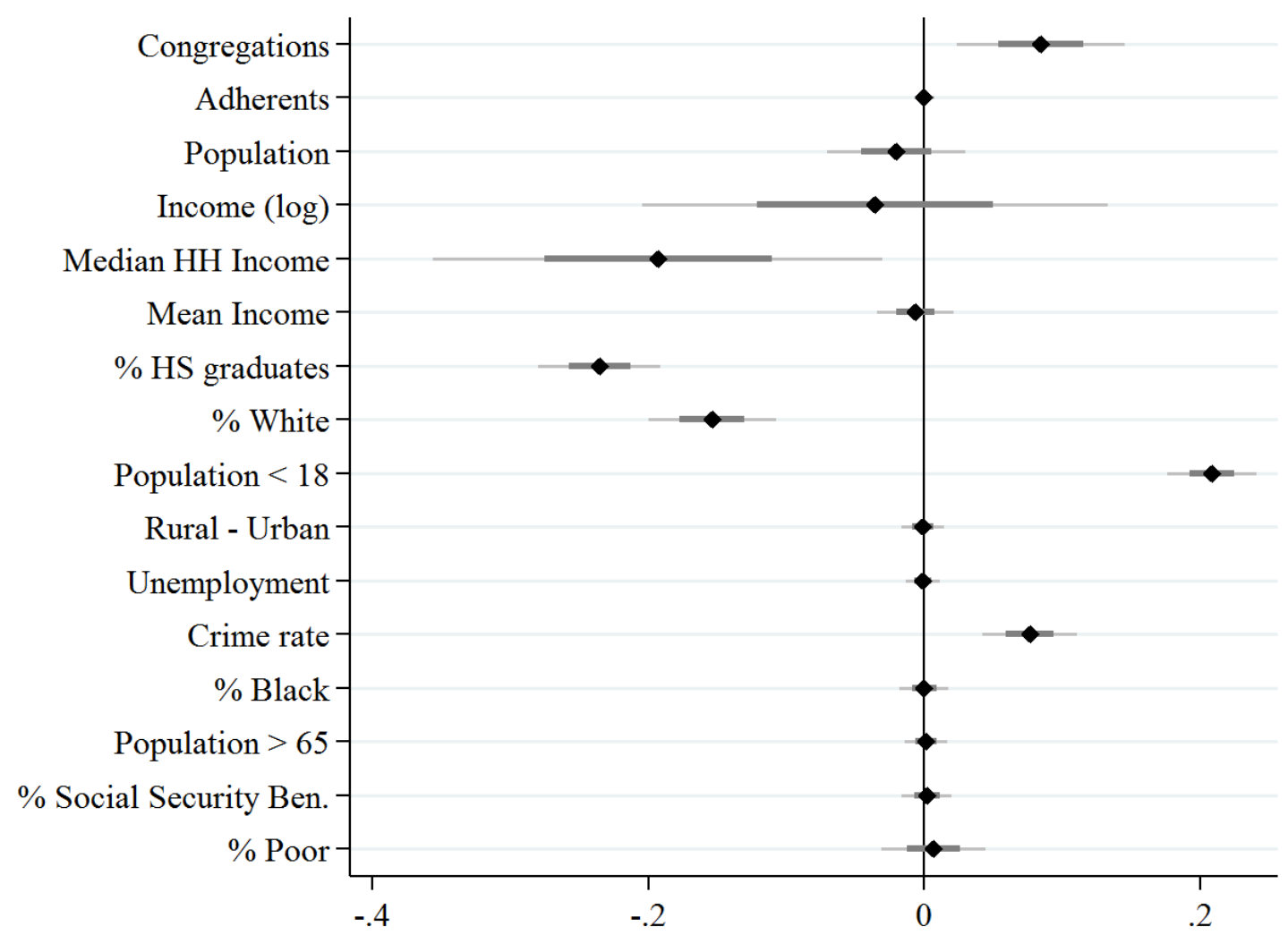


The BMA method can also be applied to the subgroup analyses, and full results are in Table A2 in the appendix. The main finding is that the religious environment appears to be a robust influence for white and Hispanic teens, but less so for black teens, for whom the county-level income, youth and crime rate are most clearly related to teenage birth rates. The results also suggest that the speculative result regarding a more nuanced impact of religious membership and diversity on black teenage birth rates appears to stand on less solid empirical footing.

In sum, the results presented here provide robust support for the Increase-Hypothesis, and against the abstinence mechanism and Reduction-Hypothesis. Teenage birth rates are higher in counties with a more religious environment. There is also considerable variation for different subgroups, and the relationship between religion and teenage childbirth appears to be most pronounced for white teenagers.

\section{Conclusion}

Is there a relationship between living in a religious environment and teenage childbirth? This article suggests that a more religious environment may lead to an increase in teenage childbirth, possibly through effects on contraceptive use, abortion and norms regarding fertility decisions.

Using county-level data, the analysis presented here provides evidence for a positive relationship between the teenage birth rate and the religious environment, measured as the countylevel density of religious congregations. These results hold when including a variety of other important predictors, as well as controlling for unobserved heterogeneity using state fixed effects. The results also indicate that there is heterogeneity with respect to racial/ethnic subgroups, with the effect of religion on birth rates being most pronounced for white teenagers. Finally, using Bayesian Model Averaging, it can be shown that results are robust with respect to model specification choices.

There are of course some important limitations to the analysis presented here. First of all, it provides a test of the general association between the county-level religious environment and teenage birth rates. A next step for future work could be to more directly test and tease apart the individual 
mechanisms discussed here, particularly regarding questions of intended and unintended pregnancies, contraceptive use, and abortion.

Similarly, like any ecological study that uses aggregated behavioral patterns, it is threatened by ecological fallacy-type problems. While the results are convincing on the aggregate level, this does not constitute proof that it is indeed the teens from religious families doing the childbearing. More research is needed here, and while the ideal study would be able to link anonymized individual administrative and health records with survey data, as is possible in some countries, for the U.S., large-scale health surveys might be the most promising way forward. That being said, the use of county-level data is the most fine-grained analysis possible within the limitations of administrative data on births, and it is arguably less at risk from this confounding problem than studies at higher levels of aggregation, such as those using the U.S. states, or cross-national comparisons.

One further limitation concerns the operationalization of the religious environment. As discussed in the data and methods section above, the study uses the number of congregations per 1000 population in a county, which is effectively a measure of the density of religious service providers, rather than a direct measure of religiosity. The problem with more direct, survey-based measures, such as church attendance, is that these generally do not allow for fine-grained, county-level estimates due to too few respondents per geographic unit; and Blanchard et al (2014) show that congregation density is a very good predictor of more direct religiosity measures. The adherents measure is based on self-reported data from the congregations, and not without problems (cf. Finke and Scheitle 2005). Given the results presented here, a general influence of the religious environment on teenage birth rates is hard to dispute, but it is of course possible that the process linking it to teenage birth rates is more complex: The overall null-effect of the adherents measure and the strong influence of the congregation density could also suggest that it is specifically religious diversity that affects teenage birth rates. Given the data, this is of course speculative, but considering for example the growth of more fundamentalist Christian congregations, future research could try to investigate in more detail the differentiated effects of specific aspects of the religious landscape on adolescent sexual behavior and teenage childbearing. 
Overall, based on the results presented here, there are a variety of interesting avenues for future research. For example, what is the exact causal mechanism that relates the religious environment to teenage childbearing (intended pregnancies, contraception, abortion?), and is it religiosity per se, or rather specific aspects of the religious landscape such as religious diversity or certain types of congregations that are most relevant?

The final question to be discussed, concerns consequences for public health and social policy. This article presents an empirical perspective on the relationship between the religious environment and teenage birth rates that should inform future research on the topic, and may be of direct use to policy makers. The stated goal of the CDC (2015) is teen pregnancy prevention, and understanding the breadth of ecological factors that affect teenage birth rates is paramount to tackling this policy problem. The data analysis provides additional robust support for a variety of well-known risk factors, such as lack of education, low income, and poverty. One goal for social policy in this field has to be to address these risk factors. Kirby and Lepore (2007) provide an exhaustive overview of individual, family and community correlates of teenage childbirth, as well as an insightful discussion of which of these factors can actually be influenced. One contribution of this article lies in pointing out the large regional variation, even within the fifty states, which means that local, community focused solutions have to be found. Specifically, if the local religious landscape in general, and perhaps specific congregations in particular, are relevant for these outcomes, than these community factors have to be taken into account in the policy making process. This may for example affect what message educational programs can send without being rejected by local communities. As an example of a perhaps more widely acceptable aspect of education programs, with respect to intended pregnancies, more emphasis could be placed on stressing the value of finishing school before starting a family. In general, from a public health perspective, policy has to make sure contraception and reproductive health services as well as educational programs are widely available. The main question then becomes where educational and other resources can be deployed to greatest effect. Based on the findings from this study, more religious environments are one of the areas that, apart from economically and educationally disadvantaged areas, should be targeted. 


\section{References}

Achen, C. H. (2002). Toward a new political methodology: Microfoundations and art. Annual Review of Political Science, 5(1):423-450.

Ahn, N. (1994). Teenage childbearing and high school completion: Accounting for individual heterogeneity. Family Planning Perspectives, 26(1):17-21.

ARDA - The Association of Religion Data Archives (2008). United States - Largest Religious Groups. Retrieved on 05/20/2008 from: http://www.thearda.com/internationalData/countries/Country_234_1.asp

ASARB - Association of Statisticians of American Religious Bodies (2000) Religious Congregations and Membership Study. Retrieved on 05/19/2008 from: http://www.thearda.com/Archive/Files/Descriptions/RCMSCY.asp

Averett, S. L., Rees, D. I., \& Argys, L. M. (2002). The impact of government policies and neighborhood characteristics on teenage sexual activity and contraceptive use. American Journal of Public Health, 92(11), 1773-1778.

Baldwin, W. and Cain, V. S. (1980). The children of teenage parents. Family Planning Perspectives, 12(1):34-43.

Barro, R. J. and Mccleary, R. M. (2003). Religion and economic growth across countries. American Sociological Review, 68(5):760-781.

Beck, S. H., Cole, B. S., and Hammond, J. A. (1991). Religious heritage and premarital sex: Evidence from a national sample of young adults. Journal for the Scientific Study of Religion, 30(2):173-180.

Blanchard, T., Stroope, S., \& Tolbert, C. (2014). Bringing the Congregations Back in: Religious Markets, Congregational Density, and American Religious Participation. Religions, 5(3), 929947.

Brewster, K. L., Cooksey, E. C., Guilkey, D. K., \& Rindfuss, R. R. (1998). The changing impact of religion on the sexual and contraceptive behavior of adolescent women in the United States. Journal of Marriage and the Family, 493-504.

Centers for Disease Control and Prevention (2005) Natality public-use data on CDC WONDER Online Database, 1995 - 2002. http://wonder.cdc.gov/natality.html (05/20/2008)

Centers for Disease Control and Prevention (2015) Reproductive Health: Teen Pregnancy. http://www.cdc.gov/teenpregnancy/about/index.htm (01/07/2015)

Crane, J. (1991). The epidemic theory of ghettos and neighborhood effects on dropping out and teenage childbearing. American journal of Sociology, 1226-1259.

Darroch, J. E., Singh, S., and Frost, J. J. (2001). Differences in teenage pregnancy rates among five developed countries: The roles of sexual activity and contraceptive use. Family Planning Perspectives, 33(6):244-281.

De Luca, G., \& Magnus, J. R. (2011). Bayesian model averaging and weighted-average least squares: Equivariance, stability, and numerical issues. Stata Journal, 11(4), 518-544. 
Evans, D. T., Cullen, F. T., Dunaway, G. R., and Burton, V. S. (1995). Religion and crime reexamined: The impact of religion, secular controls, and social ecology on adult criminality. Criminology, 33(2):195-224.

Finer, L. B., \& Henshaw, S. K. (2006). Disparities in Rates of Unintended Pregnancy In the United States, 1994 and 2001. Perspectives on Sexual and Reproductive Health, 38(2), 90-96.

Finke, R., \& Scheitle, C. P. (2005). Accounting for the uncounted: Computing correctives for the 2000 RCMS data. Review of Religious Research, 5-22.

Gelman, A. (2009). Red state, blue state, rich state, poor state: why Americans vote the way they do. Princeton University Press.

Geronimus, A. T. and Korenman, S. (1993). The socioeconomic costs of teenage childbearing: Evidence and interpretation. Demography, 30(2):281-290.

Gold, R., Kennedy, B., Connell, F., and Kawachi, I. (2002). Teen births, income inequality, and social capital: developing an understanding of the causal pathway. Health \& Place, 8(2):77-83.

Goldscheider, C. and Mosher, W. D. (1991). Patterns of contraceptive use in the United States: The importance of religious factors. Studies in Family Planning, 22(2):102-115.

Henshaw, S. K. (1997). Teenage abortion and pregnancy statistics by state, 1992. Family Planning Perspectives, 29(3):115-122.

Hoffman, S. D., Foster, M. E., and Furstenberg, F. F. (1993). Reevaluating the costs of teenage childbearing. Demography, 30(1):1-13.

Jones, R. K., Purcell, A., Singh, S., \& Finer, L. B. (2005). Adolescents' reports of parental knowledge of adolescents' use of sexual health services and their reactions to mandated parental notification for prescription contraception.Journal of the American Medical Association, 293(3), 340-348.

Joyce, T., \& Kaestner, R. (1996). State reproductive policies and adolescent pregnancy resolution: the case of parental involvement laws. Journal of Health Economics, 15(5), 579-607.

Kirby, D., Coyle, K., \& Gould, J. B. (2001). Manifestations of poverty and birthrates among young teenagers in California zip code areas. Family planning perspectives, 63-69.

Kirby, D., Lepore, G., \& Ryan, J. (2005). A matrix of risk and protective factors affecting teen sexual behavior, pregnancy, childbearing, and sexually transmitted disease. The National Campaign to Prevent Teen Pregnancy, Washington, DC.

Kirby, D. \& Lepore, G. (2007). Sexual risk and protective factors.Factors affecting teen sexual behavior, pregnancy, childbearing and sexually transmitted disease: Which are important. ETR Foundation Report.

Kirby, Douglas B. "The impact of abstinence and comprehensive sex and STD/HIV education programs on adolescent sexual behavior." Sexuality Research \& Social Policy 5.3 (2008): 1827.

Leamer, E. E. (1985). Sensitivity analyses would help. The American Economic Review, 75(3):308313.

Levine, P. B. (2003). Parental involvement laws and fertility behavior. Journal of health economics, 22(5), 861-878. 
Liao, H. H., Wang, H., \& Laymon, P. (1999). Predicting teen live birth rates using selected censusderived indicators, Lancaster County, South Carolina, 1990. Journal of Public Health Management and Practice, 5(2), 21

Magnus, J. R., Powell, O., \& Prüfer, P. (2010). A comparison of two model averaging techniques with an application to growth empirics. Journal of Econometrics, 154(2), 139-153.

Montgomery, J. M., \& Nyhan, B. (2010). Bayesian model averaging: Theoretical developments and practical applications. Political Analysis, 18(2), 245-270.

Moore, K. A. (1978). Teenage childbirth and welfare dependency. Family Planning Perspectives, 10(4):233-235.

Moore, K. A., Myers, D. E., Morrison, D. R., Nord, C. W., Brown, B., and Edmonston, B. (1993). Age at first childbirth and later poverty. Journal of Research on Adolescence, 3(4):393-422.

Mosher, W. D., Jones, J., \& Abma, J. C. (2012). Intended and unintended births in the United States: 1982-2010. Natl Health Stat Report, (55), 1-28.

Norrander, B., \& Wilcox, C. (1999). Public opinion and policymaking in the states: The case of postRoe abortion policy. Policy Studies Journal, 27(4), 707.

Olausson, P. O., Cnattingius, S., and Haglund, B. (1999). Teenage pregnancies and risk of late fetal death and infant mortality. BJOG: An International Journal of Obstetrics and Gynaecology, 106(2):116-121.

Olausson, P. O., Haglund, B., Weitoft, G. R., and Cnattingius, S. (2004). Premature death among teenage mothers. BJOG: An International Journal of Obstetrics and Gynaecology, 111(8):793-799.

Pickett, K. E., Mookherjee, J., \& Wilkinson, R. G. (2005). Adolescent birth rates, total homicides, and income inequality in rich countries. American Journal of Public Health, 95(7), 1181.

Putnam, R. D. (2000). Bowling Alone: The Collapse and Revival of American Community. New York: Simon \& Schuster.

Sala-I-Martin, X. X. (1997). I just ran two million regressions. The American Economic Review, 87(2):178-183.

Santelli, J., Ott, M. A., Lyon, M., Rogers, J., Summers, D., \& Schleifer, R. (2006). Abstinence and abstinence-only education: a review of US policies and programs. Journal of Adolescent Health, 38(1), 72-81.

Singh, S., Darroch, J. E., and Frost, J. J. (2001). Socioeconomic disadvantage and adolescent women's sexual and reproductive behavior: The case of five developed countries. Family Planning Perspectives, 33(6):251-289.

Srikanthan, A., \& Reid, R. L. (2008). Religious and cultural influences on contraception. Journal of Obstetrics and Gynaecology Canada, 30(2), 129.

Stewart, J. (2003). Mommy Track: The Consequences of Gender Ideology and Aspirations on Age At First Motherhood, The. ournal of Sociology and Social Welfare 30(2): 3-30.

Studer, M. and Thornton, A. (1987). Adolescent religiosity and contraceptive usage. Journal of Marriage and the Family, 49(1):117-128.

The Washington Post (1995). Transcript of the 1995 State Of The Union Address. http://www.washingtonpost.com/wp-srv/politics/special/states/docs/sou95.htm (09/07/2015) 
Tomal, A. (2001). The effect of religious membership on teen abortion rates.Journal of Youth and Adolescence, 30(1), 103-116. 


\section{Appendix}

Table A1: Summary Statistics

\begin{tabular}{lrrrr}
\hline & Mean & SD & Min & Max \\
\hline Teen birth rate per 1000 women aged 15-19 & 44.5 & 18.6 & 6.4 & 111.6 \\
Congregations per 1000 inhabitants & 0.90 & 0.43 & 0.32 & 2.69 \\
Adherents (\% of pop) & 0.49 & 0.12 & 0.00 & 0.96 \\
Population & 552771 & 800034 & 58610 & 9519338 \\
Median Household Income (\$) & 44375 & 10406 & 24855 & 84009 \\
\% Poor & 0.10 & 0.04 & 0.03 & 0.39 \\
\% Population under 18 & 0.25 & 0.03 & 0.15 & 0.36 \\
Rural-Urban & 2.25 & 1.44 & 1.00 & 7.96 \\
\% Highschool graduates & 0.82 & 0.06 & 0.50 & 0.95 \\
\% White & 0.79 & 0.15 & 0.21 & 0.98 \\
\hline
\end{tabular}

Table A2: Results of BMA analysis for all subgroups

\begin{tabular}{lrrrrrrrrr}
\hline & \multicolumn{3}{c}{ White } & Teenagers & \multicolumn{3}{c}{ Black Teenagers } & \multicolumn{3}{c}{ Hispanic Teenagers } \\
\hline & Mean & SE & PIP & Mean & SE & PIP & Mean & SE & PIP \\
\hline Congregations & 0.150 & 0.028 & 1.00 & 0.000 & 0.022 & 0.05 & 0.603 & 0.137 & 1.00 \\
Adherents & 0.008 & 0.017 & 0.24 & -0.038 & 0.073 & 0.26 & -0.003 & 0.025 & 0.06 \\
Population & -0.006 & 0.015 & 0.17 & 0.022 & 0.058 & 0.17 & 0.207 & 0.135 & 0.78 \\
Income & -0.266 & 0.041 & 1.00 & -0.524 & 0.106 & 1.00 & 0.015 & 0.071 & 0.10 \\
\% HS graduates & -0.082 & 0.043 & 0.87 & -0.031 & 0.084 & 0.17 & -0.088 & 0.153 & 0.31 \\
\% White & 0.012 & 0.026 & 0.23 & -0.016 & 0.053 & 0.13 & -0.045 & 0.130 & 0.16 \\
Population < 18 & 0.175 & 0.022 & 1.00 & 0.343 & 0.086 & 0.99 & 0.070 & 0.107 & 0.37 \\
Rural - Urban & -0.037 & 0.041 & 0.52 & -0.038 & 0.092 & 0.19 & 0.039 & 0.103 & 0.17 \\
Unemployment & -0.023 & 0.028 & 0.47 & -0.069 & 0.101 & 0.38 & -0.049 & 0.106 & 0.23 \\
Crime rate & 0.024 & 0.027 & 0.52 & 0.280 & 0.083 & 0.98 & 0.359 & 0.090 & 1.00 \\
\% Black & -0.053 & 0.040 & 0.71 & 0.006 & 0.034 & 0.08 & -0.094 & 0.199 & 0.27 \\
Population > 65 & -0.042 & 0.038 & 0.65 & 0.168 & 0.169 & 0.55 & -0.015 & 0.109 & 0.08 \\
\% Social Security & -0.012 & 0.034 & 0.26 & 0.152 & 0.180 & 0.47 & 0.024 & 0.124 & 0.10 \\
\% Poor & -0.035 & 0.049 & 0.41 & -0.004 & 0.038 & 0.05 & -0.268 & 0.197 & 0.73 \\
\% Hispanic & -0.236 & 0.039 & 1.00 & -0.522 & 0.086 & 1.00 & 0.592 & 0.213 & 0.93 \\
\% Commuters & -0.001 & 0.005 & 0.06 & -0.150 & 0.093 & 0.80 & 0.005 & 0.027 & 0.07 \\
\hline
\end{tabular}

Notes: Results of Bayesian Model Averaging procedure over all possible model combinations for subgroups. Dependent Variable: Births per $100 ' 000$ population. All independent variables are z-standardized to allow direct comparison. Mean is the average coefficient estimate, over all models, weighted. SE is the standard deviation of the posterior distribution. PIP is the posterior inclusion probability (cf. DeLuca and Magnus 2011, Magnus et al 2010). 